\title{
A crônica de Benjamim Costallat: uma nova ideia de literatura para a ampliação do público leitor por meio de jornais cariocas, nos anos de 1920
}

\author{
Andréa Portolomeos*
}

\section{Resumo}

Este artigo discute a produção de Benjamin Costallat como cronista de jornais cariocas nos anos de 1920 que, em diálogo com discussões realizadas na Europa sobretudo pelo Futurismo, encampava um projeto para ampliação do público leitor de literatura entre nós, abrandando os efeitos de uma modernização conservadora praticada pelos governantes da República Velha. Costallat concebia que, ao lado da urbanização do início do século XX, registrava-se uma modificação na sensibilidade dos novos grandes aglomerados urbanos. Essa ideia configura seus textos, inaugurando em suas crônicas uma linguagem marcada pela velocidade e pela imagem do novo cenário citadino, sem precedentes no universo literário brasileiro. $\mathrm{O}$ artigo pretende abordar como o cronista trabalha à revelia de um conceito tradicional da cultura e do literário, dando origem a uma importante ruptura estética no Brasil que implicou para além de uma exclusiva renovação da linguagem artística - a utilização de novos suportes, como o jornal, e de novas tecnologias, como o cinema. A produção de Costallat constitui uma nova manifestação literária nos anos de 1920 que não deve ser avaliada estritamente segundo os critérios estéticos adotados pela crítica modernista canônica. É necessário analisar a partir de outras perspectivas esses textos que fogem ao convencionalismo das categorias de arte tradicional, sob

\footnotetext{
Universidade Federal de Lavras (UFLA). Doutora, professora associada na graduação e pós-graduação em Letras, https://orcid. org/0000-0001-7298-5695.
} 
pena de negação da reinvenção de uma prática vanguardista no Brasil que lança luzes sobre as incongruências de um projeto autoritário de modernização entre nós.

Palavras-chave: Benjamim Costallat. Crônica. Formação de leitores. Nova concepção de cultura e literatura.

\title{
The Chronicle of Benjamim Costallat: A New Literature Idea for the Expansion of the Reader Public Through Carioca Newspapers in the 1920's
}

\begin{abstract}
This article discusses the production of Benjamim Costallat as a columnist for newspapers in Rio de Janeiro (carioca newspapers) in the 1920s who, in dialogue with discussions held in Europe, especially by Futurism, took on a project to expand the readership of literature among us, mitigating the effects of a conservative modernization practiced by the rulers of the Old Republic. Costallat conceived that, alongside the urbanization of the early 20th century, there was a change in the sensibility of the new large urban agglomerations. This idea sets his texts, ushering in his chronicles a language marked by speed and image in the new city scenery, unprecedented in the Brazilian literary universe. The article intends to address how the chronicler works opposing the traditional concept of culture and literature, giving rise to an important aesthetic rupture in Brazil which implied - in addition to an exclusive renewal of artistic language - the use of new media, such as newspapers and new technologies, such as cinema. Costallat's production constitutes a new literary manifestation in the 1920s that should not be strictly evaluated according to the aesthetic criteria adopted by canonical modernist criticism. It is necessary to analyze these texts, from other perspectives,
\end{abstract}


which escape the conventionality of traditional art categories under penalty of denying the reinvention of an avant-garde practice in Brazil that sheds light on the incongruities of an authoritarian modernization project among us.

Keywords: Benjamim Costallat. Chronicle. Reader formation. New conception of culture and literature.

Recebido em: 29/09/2021 // Aceito em: 23/12/2021. 


\section{Introdução}

Benjamim Delgado de Carvalho Costallat, carioca educado em Paris, colaborou intensamente como cronista, na década de 1920, com alguns jornais do Rio de Janeiro, entre eles a Gazeta de Notícias e o Jornal do Brasil. Em vez de trabalhar seus textos numa esfera normativizada, regida por critérios exclusivamente estéticos, como nossos vanguardistas canônicos, optou por popularizar a literatura com intuito de abarcar um maior número de leitores e, para isso, utilizava novos suportes mercadológicos como as folhas diárias, a propaganda e sua editora. Entretanto, este artigo se limita a discutir a produção de Costallat como cronista, em diálogo com propostas de vanguardas europeias e tendo em vista uma ampliação do público leitor de literatura.

Costallat atualizava entre nós discussões realizadas na Europa sobretudo pelo Futurismo. Marinetti, fundador desse movimento de vanguarda italiano, concebia que, ao lado da transformação industrial, ocorrida no início do século XX, registrava-se uma transformação na sensibilidade dos novos grandes aglomerados urbanos. Assim sendo, segundo ele, era necessária a superação das velhas elites intelectuais em resposta às novas exigências culturais da sociedade de massa. Ou seja, era tempo de transformar o papel tradicional do artista encastelado na sua torre de marfim. Benjamim Costallat percebia esses novos tempos e suas diferentes reinvindicações. Somado a isso, era sensível à nossa particular modernização, que não havia cumprido seu papel ilustrador - tendo em vista que não tínhamos um público numeroso de leitores - e a literatura que aqui se praticava, para um grupo muito restrito, só contribuía para a manutenção desse quadro. 
A crônica de Benjamim Costallat: uma nova ideia de literatura para a ampliação do público leitor por meio de jornais cariocas, nos anos de 1920

Segundo Peter Bürger (2019), as propostas de vanguarda caracterizam-se pela crítica à instituição arte segundo suas convenções burguesas: “[...] Com os movimentos de vanguarda, o subsistema artístico chega ao estágio da autocrítica. O dadaísmo não critica mais as tendências artísticas precedentes, mas a instituição da arte tal como se formou na sociedade burguesa." Assim sendo, nosso cronista pode ser analisado sob tal perspectiva, já que trabalhava à revelia de um conceito tradicional da cultura e do literário, professado pelos nossos modernistas canônicos da década de 1920 .

Ao voltar de seus estudos na Europa, ainda muito jovem, Costallat começa a fazer crítica musical e teatral no jornal $\mathbf{O}$ Imparcial. Em 1918, publica uma seleção desses textos sob o título Da Letra $\mathbf{F}, \mathbf{n}^{\mathbf{0}} \mathbf{2}$, numa referência à cadeira que ocupava, como crítico, no Theatro Municipal do Rio de Janeiro. Em 1919, aos 20 anos, inicia sua longa carreira de cronista do Jornal do Brasil. Paralelamente, colabora com outros jornais e revistas do Rio como a Gazeta de Notícias e Fon-Fon e ainda com jornais paulistas, como o Jornal do Comércio, no qual assinava uma crônica aos domingos. Escrevia ainda esporadicamente para os jornais italianos, como o carioca La Patria degli Italiani e os paulistas Il Piccolo e Fanfulla.

O cronista foi um animador do nosso cenário cultural no início dos anos de 1920. Chegou a conciliar as atividades de escritor, editor e dono de livraria, o que nos remete para a sua diferente concepção de cultura entendida como processo dinâmico, permanentemente renovador, para o qual um grande público ativo precisava contribuir. A ideia de literatura

\footnotetext{
1 Nossa tradução para: “con los movimientos de vanguardia el subsistema artístico alcanza el estadio de la autocrítica. El dadaismo [...] ya non critica las tendencias artísticas precedentes, sino la institución arte tal y como se ha formado en la sociedad burguesa." (BÜRGER, 2019, p. 62).
} 
encampada por ele afastava-se assim da literatura popular tradicional, marcada por um forte localismo, e também da literatura consagrada por instituições como escolas, museus e salões de arte. Tratava-se de expressão de uma cultura média que já se traduzia no folhetim, na publicidade e no cinema e que inventava outros critérios de produção e difusão.

\section{Contribuições e impasses do Futurismo para as propos- tas de Costallat}

No contexto do início do século XX, o campo de produção erudita encontra-se cada vez mais tensionado pelo mercado e, sendo assim, procura identificar-se como único espaço legitimador de cultura. Analisando um universo mais amplo, Pierre Bourdieu (apud ORTIZ, 2001) associa esse processo de consagração artística à consagração religiosa. Segundo ele, as academias, as universidades, as revistas constituem instâncias glorificadoras da obra do mesmo modo que a Igreja e seus sacramentos instituem um caráter sagrados dos objetos profanos (ORTIZ, 2001). Dessa forma, Renato Ortiz observa que é necessário pensar nas tensões que se estabelecem entre campos culturais distintos e relacioná-las a esse processo consagrador. Assim, o simples antagonismo entre cultura erudita e de mercado precisa ser repensado mediante uma relação de poder (ORTIZ, 2001).

Ortiz (2001), estudando o discurso de artistas franceses do século XIX, avalia uma preocupação com a manutenção do seu estatuto tradicional. A Revolução Francesa e a industrialização haviam trazido a classe operária para a cena das grandes cidades, o que implicou um enfrentamento entre posições e direitos. Essa 
A crônica de Benjamim Costallat: uma nova ideia de literatura para a ampliação do público leitor por meio de jornais cariocas, nos anos de 1920

ameaça potencial da nova classe se efetivava mediante greves, barricadas e, a partir de 1848, mediante o voto. O crítico revela, na fala dos intelectuais da época, um preconceito estético contra a multidão que decorreria de um conflito político. Barbey d'Aurevilly (apud ORTIZ, 2001, p. 73), por exemplo, defendia que: "[...] a democracia de retrato - brutal e mentirosa -, esta arte de quatro tostões colocada à disposição da indigência vaidosa de um século de barateamento e de bugigangas, havia aniquilado as coisas grandiosas do passado.".

A fotografia, praticada pelo homem comum, dessacralizava a aura do velho artista movido por um talento individual. Ainda nesse sentido, Renato Ortiz (2001) cita os textos de Baudelaire sobre o Salão de 1859 e os de Sainte-Beuve sobre a literatura industrial (BEUVE, 1992), nos quais a multidão das metrópoles pode ser lida como degradante. Na discussão sobre o caráter artístico da fotografia, Baudelaire argumenta: "Se se permitir que a fotografia substitua a arte em algumas de suas funções, em breve ela a suplantará - ou a corromperá - completamente, graças à aliança natural que encontrará na estupidez da multidão [...]" (BAUDELAIRE, 1988, p. 73). E Sainte-Beuve (1992) mostrase preocupado com o advento da democratização literária, pois, à medida que a multidão se apropriava da obra, via jornal, esta tendia a tornar-se superficial, para atingir um número cada vez maior de leitores. Em suma, segundo o autor, a arte corromperse-ia ao se beneficiar de processos industriais e capitalistas:

Devemos nos resignar a novos hábitos, à invasão da democracia literária, bem como ao advento de todas as outras democracias. Não importa que soe mais evidente na literatura. Escrever e imprimir será cada vez menos uma característica distintiva. Com nossos costumes eleitorais e industriais, todo mundo, pelo menos uma vez na vida, terá sua página, seu discurso, seu prospecto, 
seu brinde, será um autor. Daí para a novela, é só uma etapa. Por que não eu também? Todo mundo disse para si mesmo. ${ }^{2}$

Embora essa aproximação entre arte e mercado possa de fato representar um risco de desestabilização de uma hierarquia artística socialmente constituída, o próprio Ortiz matiza tal interpretação da cultura citadina considerado que o antagonismo entre arte e sociedade não se restringe a uma discussão de interesses particulares. Segundo o crítico, a ideia de superioridade de uma arte não se reduz a uma estratégia de distinção, mas engloba um elemento de crítica. Nesse sentido, a escola de Frankfurt, quando recusava um espaço predeterminado pelas forças produtivas, abria para a arte perspectivas de contestação das forças históricas que a realizavam e, ao mesmo tempo, a sufocavam (ORTIZ, 1991).

Assim, uma forte contradição se instaura no artista, no contexto da modernização, cujo produto revela-se impregnado dessa nova cultura citadina. Sabemos que Baudelaire, apesar de sua atitude defensiva, assumiu posturas inovadoras. Se a obra, com os novos meios de reprodução em massa, perdia seu caráter sacralizante, o poeta francês dispensava sua antiga torre de marfim, criando um novo tipo de lírica voltada para o referente urbano. Jorge Schwartz, analisando a produção do poeta francês nota: "Depois do poeta de Les Fleurs du Mal, opera-se gradualmente uma transferência do ponto de vista temático que se traduz na passagem do culto do eu ao culto do objeto [...]" (SCHWARTZ,1983, p. 3).

\footnotetext{
2 Nossa tradução para: II faut bien se résigner aux habitudes nouvelles, à l'invasion de la démocratie littéraire comme à l'avènement de toutes les autres démocraties. Peu importe que cela semble plus criant en littérature. Ce sera de moins en moins un trait distinctif que d'écrire et de faire imprimer. Avec nos moeurs électorales, industrielles, tout le monde, une fois au moins dans sa vie, aura eu sa page, son discours, son prospectus, son toast, sera auteur. De là à faire un feuilleton, il n'y a qu'un pas. Pouquoi pas moi aussi? Se dit chacun. (BEUVE, 1992, p.185)
} 
Segundo Walter Benjamim (1975), a ideia da massa é algo inerente ao texto do poeta francês, ainda que esse articule paradoxalmente suas defesas contra a atrofia progressiva da experiência individual. A multidão é intrínseca ao poeta e à sua produção:

Em os Tableaux Parisiens pode-se verificar, quase sempre, a presença misteriosa de uma massa. Quando Baudelaire toma o crepúsculo matutino como tema, há nas ruas desertas algo do "silêncio de um formigueiro" que Hugo pressente na Paris noturna. Basta que Baudelaire pouse o olhar sobre as pranchas dos atlas anatômicos, expostas à venda nos empoeirados cais do Sena, para que em suas folhas a massa dos defuntos tome, inadvertidamente, o lugar em que antes apareciam esqueletos isolados. (BENJAMIM, 1975, p. 48).

Para Benjamim Costallat, a multidão também está inseparavelmente ligada ao texto. Na medida em que administra o gênero crônica, que tem como suporte os jornais, não pode deixar de contar com essa nova variante da vida moderna. Nesse sentido, sua narrativa é marcada pelo dinamismo característico dos grandes aglomerados nas ruas:

Meus pêsames aos banhistas. Meus pêsames aos amadores de pernas. Meus pêsames aos dignos cidadãos, que à hora do banho do Flamengo, se encostam à amurada do cais em atitude contemplativa diante da plástica alheia. O banho "Ba-ta-clan" morreu. E quem quiser ver pernas tem mesmo que ir para a avenida. (COSTALLAT, 1924, p.161).

Além disso, a massa urbana muitas vezes torna-se temática nos textos do autor:

E na barulhada confusa da rua, surge, finalmente, a cena imprevista, a cena deliciosa de emoção, que faz da rua, da calçada, dessa coisa inanimada, feita de pedra e de 
cimento, o quadro mais variado onde os atores mais sensacionais desfilam. A calçada é o palco maravilhoso onde os atores não se pintam nem fingem. São tais quais são. (COSTALLAT, 1924, p. 67).

O movimento de vanguarda Futurista colaborava na reavaliação da posição conservadora sobre a multidão, mas seu posicionamento ambíguo se revelou faca de dois gumes: se, de um lado, abriu portas para discussões até hoje contemporâneas, de outro, deu margem para a atuação fascista. Nesse caso, a grande massa foi reduzida a uma condição passiva, tornou-se tão somente um material maleável organizado para o triunfo do artista-plástico/político. Dirá Mussolini (apud JAY, 2003, p.148) posteriormente:

Quando a massa fica como cera nas minhas mãos ou quando me confundo e quase sou esmagado, me sinto parte da massa. Mesmo assim, persiste em mim um certo sentimento de aversão, como o que o artista experimenta pelo gesso que modelo. $\mathrm{O}$ escultor às vezes não quebra o bloco de mármore em mil pedaços porque não consegue dar forma à visão que concebeu? ${ }^{3}$

Contudo é inegável que o movimento fomentou um novo campo de atuação para a cultura na sociedade moderna ao considerar o grande público. Mario de Micheli, importante crítico das vanguardas italianas, em Le avanguardie artistiche del Novecento, analisa as contradições que caracterizam o futurismo. Segundo ele, a formação do movimento é demasiadamente complexa visto que seus participantes vinham de extrações anárquicas, comunistas e nacionalistas. Marinetti, como admirador das ideias anárquicas, proclamava um gosto

\footnotetext{
3 Nossa tradução para: Cuando las massas son como cera en mis manos o cuando me confundo con ellas y quedo casi aplastado por ellas, me siento parte de la massa. Aun así persiste en mi cierto sentimiento de aversión, como el que experimenta el artista por el yeso que modelo. ¿No rompe a veces el escultor en mil pedazos el bloque de mármol porque no puede darle la forma de la visión que concibió?
} 
A crônica de Benjamim Costallat: uma nova ideia de literatura para a ampliação do público leitor por meio de jornais cariocas, nos anos de 1920

libertário em seus manifestos, atraindo, assim, diferentes perfis de artistas para o seu movimento de vanguarda.

De Micheli considera que um dos grandes problemas do futurismo foi a relação positivista que estabeleceu entre progresso tecnológico e humano, dispondo esses elementos sobre um mesmo plano com prejuízo para o homem. Todavia, segundo o autor, mesmo com essa marca tecnicista em sua poética, o movimento intuía e divulgava o desenvolvimento de uma nova arte que desestabilizava as convenções artísticas do oitocentos. Essas novas perspectivas foram acolhidas em muitas partes da Europa e na Rússia, onde "Maiakovski e o construtivismo tiveram, sem dúvida, mais que um impulso do futurismo italiano."4

As propostas futuristas não objetivavam apenas uma renovação estética, mas também-o que interessa particularmente para este artigo - uma revolução na ideia do produto cultural dentro da nova sociedade de massa. Nesse sentido, suas propostas aproximam-se de um conjunto de autores brasileiros que atuava no início do século XX, ao qual pertence Benjamim Costallat. De acordo com esse grupo, a ruptura estética no Brasil implicava, para além de uma renovação da linguagem artística, a utilização de novos suportes, como o jornal e a propaganda, e de novas tecnologias, como a arte gráfica e o cinema. Longe de querer resgatar em Marinetti o precursor desse filão, importanos sublinhar o caráter revolucionário, modernista, desses intelectuais brasileiros que aclimatavam entre nós discussões artísticas europeias de ponta antes mesmo do nosso consagrado movimento modernista.

4 Majakovskij e il construtivismo hanno senz'altro avuto dal futurismo italiano più di un impulso." (MICHELI, 2003, p. 246). 


\section{Benjamim Costallat e a aclimatação das propostas futu- ristas no Brasil}

A fortuna crítica sobre Benjamim Costallat hoje é quase inexistente. Entre os poucos textos que circulam, há uma apresentação da reedição da série de crônicas Mistérios do Rio, promovida pela Prefeitura do Rio de Janeiro, em 1995, escrita por Armando e Rosa Maria Gens. Esses autores seguem a tendência do estudo do historiador Nicolau Sevcenko e leem as crônicas, publicadas originalmente no Jornal do Brasil, em 1924, como expressão de uma sequência de vícios da cidade que, indiretamente, reclamava por um "saneamento social". Voltava à baila a tão discutida e não menos importante hipótese de uma literatura empenhada na política oficial do início do século, segundo a qual o Rio de Janeiro deveria tornar-se, a qualquer custo, expressão de civilidade para atrair investimento estrangeiros.

Todavia, produzir uma literatura confirmatória da administração constituída não parece ser a intenção de Costallat. Podemos ler em A Gazeta de Notícias, de 14 de março de 1924, o seguinte trecho de uma entrevista com o autor:

— Então! Qual vai ser o seu novo trabalho? Já tem algum assunto em vista? [...]

— Vai chamar-se "Os mistérios do Rio".

— Então teremos o Eugène Sue em ação...

- Qual o quê, cousa diferente. Não quero fazer obra erudita, meu amigo. O povo não gosta disso. (COSTALLAT, 1924).

Mais parece interessar ao cronista um texto capaz de expandir seu público. Assim, as suas crônicas elegiam aspectos 
marginais da cidade - como o vício do ópio, a prostituição e a jogatina - não com o propósito de ressaltar as mazelas do lugar para justificar um processo de higienização à moda Pereira Passos, mas para aguçar as curiosidades dos leitores:

Viramos o Beco do Cotovelo, o beco sinistro e fétido, com a sua ladeirinha que sobe para as ruínas do Castelo. Pouco depois estávamos na Travessia dos Ferreiros. Em pleno bairro chinês. Mas pode-se chamar aquilo um bairro? Não. É apenas uma travessa. Pequenina, estreita, tem-se a impressão de que, abrindo os braços, fecha-se o trânsito da estranha viela. As casas são bastante altas e durante o dia mal se avista o céu. O céu, para aquela pobre gente que ali vive, é apenas uma fatia, uma pequenina fatia de azul iluminado. Mas, à noite, a travessa dos ferreiros é apavorante. Mal acessa, quase escura, adivinha-se mais do que se vê. (COSTALLAT, 1990, p. 83).

Os textos não são permeados por juízos que justifiquem uma cientifização da cidade; pelo contrário, a postura do autor incomodava profundamente uma camada mais conservadora da sociedade que chegou a combater sua produção ficcional.

Em outra entrevista, publicada pelo JB na véspera da estreia da série, em 31 de abril de 1924, Costallat deixaria claro o caráter de reportagem dos textos, em resposta à preferência dos leitores: “[Os Mistérios do Rio] são absolutamente verdadeiros. Apenas olhei e narrei [...]. Todos, absolutamente todos os ambientes descritos por mim são verdadeiros, e os personagens que passam pelos Mistérios foram observados de perto." (COSTALLAT, 1924)

Como acontece muitas vezes com o narrador de João do Rio, em A alma encantadora das ruas, o cronista de Mistérios... é sempre introduzido no submundo do Rio de Janeiro dos anos 20 por um companheiro. É este quem o convida a visitar uma 
favela da cidade, a conhecer suas regras sociais e seu linguajar; é ele quem o apresenta aos chineses fumantes e comerciantes de ópio na Travessa dos Ferreiros, no centro do Rio; é ele ainda que o acompanha numa visita a uma "casa de amor" na rua de Riachuelo. Todas essas investidas, muitas feitas na calada da noite, eram instigadoras da curiosidade de pessoas comuns que partilhavam daquele espaço urbano tão sincrético quanto estimulante: "A favela, ao longe, com seus casebres minúsculos, parecia um presépio imenso. Descemos na rua da América. Uma das ruas mais sórdidas do Rio de Janeiro. Enlameada, imunda. Ligada ao Morro do Pinto pela Ponte dos Amores, a favela, com seus casebres, rebrilhava ao sol." (COSTALLAT, 1990, p. 37).

Ainda podemos notar que a série recuperava, de certa forma, o significado primordial da crônica como modalidade histórica, ultrapassando seu sentido mais recente de enfoque e comentário dos fatos do dia a dia. Costallat escrevia, ao seu modo, a história do Rio modernizado, filiando-se a um exercício de estilo cultuado na imprensa do século XX, sobretudo por Joaquim Manoel de Macedo, com Um passeio pelo Rio de Janeiro e Memórias da rua do Ouvidor. Os textos de Mistérios..., que ocupavam uma página inteira do jornal e eram ricamente ilustrados, desenvolviam sempre pequenos enredos - diferentemente dos outros escritos do cronista para o $\mathbf{J B}$ ou para outros jornais que se caracterizavam por comentários de assuntos gerais. Frei Domingos Vieira (apud COUTINHO, 2001, p. 120), ao definir a crônica, fala-nos sobre esse seu duplo potencial:

Crônicas - anais pelas ordens dos tempos, por oposição à história em que os fatos são estudados nas suas causas e nas suas consequências. - Atualmente, nos jornais, parte em que se contam os principais acontecimentos e se reproduzem os boatos numa terra; crônica política, a parte do jornal em que se referem as novas políticas. 
A crônica de Benjamim Costallat: uma nova ideia de literatura para a ampliação do público leitor por meio de jornais cariocas, nos anos de 1920

É interessante observar que a nova roupagem sem ântica para o gênero, que o vincula ao jornalismo e à literatura, só ocorreu na língua portuguesa. A transformação operou-se em Portugal ou no Brasil, no século XIX, quando se passou a publicar uma seção de comentários semanais nos jornais (COUTINHO, 2001). O sentido primitivo de crônica, ou seja, o feitio de relato histórico que assumiu a historiografia da Idade Média e do Renascimento, em todas as partes da Europa, a princípio em latim e depois nas diversas línguas vulgares, foi o que prevaleceu hoje nos vários idiomas europeus modernos, menos no português:

Em inglês, francês, espanhol, italiano, a palavra só tem este sentido: crônica é um gênero histórico. $E$, assim como crônica, "croniqueiro" e "cronista" só se empregam, relativamente a crônica, naquele sentido: eram o indivíduo que escrevia crônica. O mesmo ocorre em francês: chronique e chroniqueur. É o significado tradicional. (COUTINHO, 2001, p. 121).

A crônica como gênero do cotidiano nasce com os nossos folhetins - versão nacional do feuilleton francês -, espaço livre destinado a entreter o leitor e a dar-lhe uma pausa de descanso em meio ao tom mais solene da folha. Havia duas espécies de folhetim no oitocentos: o romance, espaço privilegiado dos rodapés do jornal em que se registrava e se comentava a vida cotidiana da província, do país e do mundo, e os folhetinsvariedades, que "eram extensos e abrangiam uma grande variedade de assuntos, sobre os quais o folhetinista ia discorrendo com aquela frivolidade inerente ao gênero, de que falam os escritores da época [...]" (LAURITO, 1993, p. 23).

A crônica jornalística visa conquistar a empatia do leitor e, nesse sentido, está comprometida com o prazer. A tarefa do cronista é, para além de trabalhar com a função referencial da 
linguagem, encenar um jogo de sedução. Nesse sentido, ficção e história fundem-se no gênero. Marta Passos, ao estudar as crônicas de José de Alencar, avalia as características próprias desse campo discursivo:

Até que ponto os textos da crônica são ficcionais, informativos ou históricos? Se a crônica fosse definida dentro de alguns desses campos discursivos, perderia parte de seu poder de persuasão. A informação transmitida pelos artigos folhetinescos, ao ser misturada à ficção, acaba adquirindo a independência das variedades - seção do jornal que, segundo Nilson Lage, apresenta assuntos que interessam por si, sem depender de acontecimentos históricos. (PASSOS, 2000, p. 15).

$\mathrm{Na}$ construção dos textos, os fatos não são simplesmente dispostos, mas selecionados criteriosamente em consonância com o público. O cronista registra momentos da vida contemporânea, comuns à população, fornecendo-lhe elementos que viabilizem uma rápida interação comunicacional entre autor e leitor. A leitura se torna mais fácil e atraente quando o leitor passa a sentir-se protagonista do enredo.

As crônicas de Costallat são preparadas para que o receptor, ao deparar-se com a página impressa, encontre ali elementos de sua realidade. Pelos seus escritos, podemos inferir que buscava a adesão de uma pequena burguesia que não tinha hábito de leitura. Abundam nas crônicas ambientes, trajes e comportamentos que remetem à atmosfera burguesa dos anos de 1920. Lê-se em A Mulher Fatal:

A mulher fatal hoje usa tailleur, um simples e sóbrio tailleur desenhando-lhe o corpo; é pequenina, quase imperceptível no meio da multidão, não faz nenhuma pose de vampiro, nem tem olhos que nunca mais se acabam [...]. A mulher fatal hoje tem apenas um palminho de cara interessante [...]. A cada passo 
encontramo-la. Pela avenida, nas casas de chá, nos dancings, em toda parte. [...] andam a passos curtos, rapidamente. Fazem compras, tomam chá e vão ao cinema como todo mundo. (COSTALLAT, 1924, p. 62).

Essa dramatização da narração in loco reforçava o caráter documental do texto, garantia de aproximação do público, e suavizava seu teor ficcional. Nesse sentido, podemos dizer que as crônicas colaboravam para a solidificação de hábitos e costumes que iam se infiltrando na cidade. Assim, o cronista pode ser analisado como fundador de novos referenciais e significações para o Rio de Janeiro na medida em que encena uma identificação perfeita entre o texto e o leitor.

Ainda em relação à construção de novos referenciais a partir do texto, observe-se, no trecho seguinte, como o mito do homem moderno - descrito por Pär Bergman (1962) como universal na cultura ocidente - ia sendo articulado em nosso país. Costallat reorganizava a imagem do homem notável com base nos novos códigos modernos e oferecia-nos um indivíduo capaz de dominar o espaço e vencer as distâncias em sua máquina voadora:

Esse Martins glorioso que nos chega de Nova York pelos ares, depois de uma viagem das mais acidentadas e das mais perigosas, batendo todos os recordes da coragem e da resistência [...]. Esse Martins que dominou o espaço e as nuvens, as distâncias e o tempo, os elementos e o acidentes, que tudo dominou e que tudo venceu e que agora nos chega, depois de ter percorrido todo o Brasil desde o Pará [...] (COSTALLAT, 1924, p. 96).

O mesmo espírito universal, estimulado sobretudo pelos novos códigos burgueses internacionais, ganhava estatuto de documento na crônica $\mathrm{O}$ homem que vai dançar.... Nesse texto, podemos resgatar aquele deslumbramento em relação às potencialidades humanas, sobre o qual também nos falava 
Bergman (1962). Tal entusiasmo se desdobra em um desejo de ultrapassagem, de superação de próprios limites, que culmina, nos esportes, com a recuperação dos jogos olímpicos e com a ideia de records.

Agora mesmo, está tentando ver o dançarino português e profissional, o jovem e esperançoso Sr. Bueno Machado, dançar enquanto tiver fôlego e pernas, ali no teatro S. Pedro, horas a fio, noite e dia, até bater o recorde mundial ou sul-americano de resistência dançante. O dançarino dançará cinco minutos de hora em hora e cansará quantas damas forem necessárias para finalizar o recorde [...] (COSTALLAT, 1924, p. 39).

Contudo, muitos desses costumes abordados por Costallat não the agradavam. Lendo suas crônicas, percebese imediatamente que estamos diante de uma figura ambígua. Por um lado, aposta nas variantes da vida moderna para o texto literário e em ações estratégicas para a ampliação da comunidade leitora. Por outro, demonstra saudosismo dos tempos idos e revela certa aversão à forte influência norte-americana que passava a concorrer e a substituir a influência francesa no Brasil. Dessa maneira, ataques ao $j a z z$, às lutas de boxe e ao cinema são também frequentes em seus escritos.

O cronista encarnava, então, dois narradores: um, debochado, satírico e divertido, mandava às favas os tradicionais procedimentos em literatura; outro, francamente saudosista, procurava resguardar um passado livre das corrupções modernas dos costumes. Assim comentou a chegada da luz elétrica na Ilha de Paquetá:

O sacrilégio rapidamente começou. Praias foram rasgadas. Foram rasgadas ruas. Árvores tiveram que se inclinar sob uma poda impiedosa. O céu atravessado de fios. Os postes cortando a paisagem. Lâmpadas de todos 
os lados, penduradas e inúteis, pretensiosas e grotescas em plena luz do dia [...] (COSTALLAT, 1922, p. 123).

Observe-se como essa polaridade do narrador é apresentada no texto por meio do entrecruzamento da técnica dinâmica de escrita e de uma temática que vai de encontro aos efeitos da modernização.

Maurício Silva analisa os romances de Costallat nesse mesmo sentido. Segundo ele, o narrador incorporava os perfis de moderno e antimoderno, visto que usava técnicas modernistas, mas, ao mesmo tempo, subvertia sua sofisticação, oferecendo ao leitor um produto de gosto popular, muitas vezes recheado de bastante erotismo, perversão e vício. Nesse sentido, Benjamim Costallat foi reconhecido por Silva como o primeiro autor kitsch da literatura brasileira:

Trata-se, sem dúvida alguma, de uma compreensão bastante pessoal da modernidade: se de um lado, o moderno manifesta-se por meio da adesão do artista aos mais inovadores recursos estéticos, por outro lado, sua obra é dotada, às vezes, de uma expectativa simbólica que denota um apego incontestável ao popularesco, em tudo oposto à dinâmica da modernidade. Daí o caráter ambíguo de sua modernidade, em que os valores mais prezados por uma suposta elite esclarecida (o cinema, o automóvel, o luxo, o poder) se mesclam inexoravelmente a valores francamente populares (o erotismo vulgar, a futilidade, a imitação barata, comportamento padrão). Nesse sentido, pode-se dizer que, pelo menos sob uma perspectiva, Benjamim Costallat pode ser considerado um moderno antimoderno [...] (SILVA, 1997, p. 107).

Contudo, levando-se em consideração a discussão anterior, parece-nos interessante avaliar até que ponto realmente esse "apego ao popularesco" é antípoda de um posicionamento vanguardista dentro do contexto específico brasileiro. O 
pensamento de Silva, apesar de seu exercício de reflexão ensaiar alternativas ao modelo tradicional de crítica, mostra-se ainda atrelado àquele rígido dualismo entre literatura erudita e popular que orientou, de modo geral, nosso cânone acadêmico.

Em relação ao cinema, o caráter ambíguo de Costallat é bem explícito. Flora Süssekind, em seu livro Cinematógrafo de Letras, destaca na obra do cronista procedimentos discursivos não convencionais, baseados numa interação com o universo tecnológico em expansão: "Costallat, rejeição à parte, de alguma forma percebe o cinema como dotado de recursos expressivos e materiais próprios e não tomados vampirescamente de empréstimo apenas àquilo que filma ou aquela que opera a câmera [...]" (SÜSSEKIND, 1987, p. 139). Embora o autor, em algumas crônicas, registre certa antipatia pelo cinematógrafo, ele é reconhecido por Süssekind como um dos primeiros autores brasileiros a utilizar literariamente os procedimentos estilísticos desse novo produto cultural das metrópoles, como os traços contidos e bem definidos na caracterização dos personagens. Assim podemos ler sua caracterização dos personagens Mutt e Jeff que faziam grande sucesso nas grandes telas da época:

Mutt e Jeff são dois traços, duas psicologias. Mutt é o magro, é o alto, desenhado em linhas compridas, através de arestas áridas, definido em ossos, realizado em ângulos, deficiente de estômago e de carnes, feito por pontinhos secos e magros, narigudo e impassível, ossudo e imperturbável, vagabundo e conceituado. [...] Jeff é o pequeno e o gordo, redondo e roliço, feito a traços confortáveis, meio ovo, meio presunto, barbudozinho, bigodeira farta e majestosa, barriga agradável, silhueta burguesa, gestos decisivos e dominadores. (COSTALLAT, 1922, p. 7). 
A crônica de Benjamim Costallat: uma nova ideia de literatura para a ampliação do público leitor por meio de jornais cariocas, nos anos de 1920

Mutt, Jeff e Cia., reunião de crônicas publicadas em sua maioria na Gazeta de Notícia, homenageia justamente essa fita de desenhos animados cujos personagens são Mutt e Jeff. Paradoxalmente, Costallat inicia seu livro com uma declaração de desamor ao cinema: "O cinema se caracteriza por um eterno vazio de sentido, um absoluto vácuo de inteligência no que descrevem com beijos e atitudes contorcidas as suas notórias notabilidades baratas [...]" (COSTALLAT, 1922, p. 5), o que confirma a ideia de Isabel Lustosa sobre o caráter ambíguo de uma geração de autores do início do século, "herdeira da contradição palpitante da maneira de ver e viver o Brasil da boêmia literária do Rio de Janeiro de seu tempo [...]"' (LUSTOSA, 2004, p. 14).

Ainda com relação às estratégias que visavam à ampliação do público, nota-se um traço de estilo destinado ao público feminino. De fato, as mulheres da pequena burguesia, no início do século, dispunham de mais tempo livre para se dedicarem à atividade da leitura. Dessa forma, Costallat engrossava as fileiras de autores jornalistas, como José de Alencar e Machado de Assis, que souberam intuir um potencial dessa parcela da população. A crônica seguinte retrata o universo feminino dos anos de 1920:

[...] a moda, rapidamente, nesta última semana, modificou por completo as silhuetas femininas. As silhuetas deliciosas com que de há muito se vinham habituando nossos olhos e nosso prazer. [...] As ruas povoadas de saiazinhas curtas, pernas nervosas, cinturas ajustadas à forma dos corpos, que iam e vinham leves e vaporosas, foram de um dia para o outro, invadidas pela austeridade de muitas saias compridas, compridas até o chão [...]. As cinturas passaram a ser baixas, muito baixas. (COSTALLAT, 1923, p. 80).

Em Mártires da elegância, os comentários acerca de uma moça que morre à custa de um regime de emagrecimento possivelmente atrairiam a atenção das senhoras: 
A silhueta feminina acompanha a última moda. A última moda é o último figurino. O último figurino é o último desenho de um costureiro parisiense. Quer dizer que o corpo das mulheres elegantes do mundo tem que se plasmar à fantasia de um senhor da Rue de la Paix que resolve hoje que elas não tenham quadris e que amanhã elas não tenham mais formas. [...] $\mathrm{E}$ as mulheres que não gostam de obedecer são mais do que obedientes num assunto que, muitas vezes, lhes prejudica a saúde e a felicidade. (COSTALLAT, 1924, p. 47).

O autor tornaria a participação das mulheres ainda mais efetiva na elaboração dos textos a partir da publicação, na sua coluna Nota, do JB, de O decálogo da mulher casada, tradução de uma crônica italiana, publicada no La Stampa, de Turim. Dizia a crônica:

Ama o teu marido acima de todas as coisas e o teu próximo o melhor que puderes. Mas lembra-te que a casa é do teu marido e não de teu próximo. Considere o teu marido como um hóspede ilustre, como um amigo precioso e não como uma pessoa a quem se contam os pequenos aborrecimentos da existência. Que a tua casa esteja sempre em ordem e a tua fisionomia sorridente quando ele chegar. Mas se ele não se aperceber logo, perdoa-1he. (COSTALLAT, 1924, p. 68).

No final do texto, ele ironicamente convidava as leitoras a colaborarem na constituição da crônica seguinte: $\mathrm{O}$ decálogo do bom marido. Houve inúmeras participações conforme nos conta o próprio cronista:

[...] tive-as [as respostas] de todos os gêneros. Sutis e comovidas. E algumas também maliciosas. O que me alarmou, porém, foi a quase unanimidade das mulheres contra os homens. [...] Entre as respostas do mesmo tom, parodiando "O decálogo da Mulher Casada" que eu publiquei, escolhi a que mais brilha pela malícia, pela perfídia e a boa e irônica fatura literária. (COSTALLAT, 1924, p. 71). 
A crônica de Benjamim Costallat: uma nova ideia de literatura para a ampliação do público leitor por meio de jornais cariocas, nos anos de 1920

Interessa analisar ainda o tipo de sintaxe privilegiado pelo autor e sua relação com a formação da comunidade leitora. Os leitores se reconheciam no andamento da narrativa que dramatizava o ritmo frenético em que viviam. Nesse sentido, o cronista seguia as trilhas abertas por João do Rio, o qual havia investido numa reforma do nosso jornalismo sisudo, tornando os textos mais ágeis. Contudo, a escrita de Costallat se mostrava mais sintética, como se revelasse uma maior intimidade com os aparelhos técnicos que iam popularizando-se. O jornalista Paulo Silveira observava em O Paiz, no início dos anos de 1920: "Nada de circunlóquios românticos, de paradas líricas. Benjamim Costallat escreve de automóvel e por isso se aproxima muito de nós futuristas que escrevemos de aeroplano [...]"(SILVEIRA, 1920). Nesse sentido, observe-se como o cronista comentava de forma direta e dinâmica o caso de um criminoso já popularmente conhecido no Rio de Janeiro como "o navalhador de pernas":

O navalhista a escolhe a dedo. Não vai assim por qualquer uma. Quando realmente encontra seu ideal, examina-lhe a perna, a meia de seda fina e transparente que a envolve e, então assim, é que se mexe. Mexe-se mesmo demais. Da um pulo como um boneco de mola, e logo, de navalha entre os dedos, vai cortando a meia e a perna que o alucinavam. Feito isso, com um gozo que deve ser imenso, o sádico desaparece. $\mathrm{O}$ bonde inteiro grita. Sua vítima vai para a assistência. E cai o pano. (COSTALLAT, 1922, p. 81).

Segundo Afrânio Coutinho, em A Literatura no Brasil, João do Rio já havia modernizado a crônica social no Brasil com suas entrevistas e reportagens, embora continuasse a explorála pela maneira tradicional em que predominava o ornamento linguístico. Contudo, Costallat foi capaz de subverter rapidamente esses resquícios líricos de fundação do gênero. Coutinho nos 
recorda que o jornal "brotou e escreveu no Brasil sob a atmosfera do Romantismo, o que contribuiu para que o acento lírico tivesse predominado sobre a crônica desde as suas primeiras manifestações [...]" (COUTINHO, 2001 p. 123). A observação do jornalista de O Paiz sobre o estilo de Costallat nos reporta imediatamente aos dois manifestos lançados por Marinetti. O primeiro, Fundação e Manifesto do Futurismo, publicado no jornal Le Figaro, em 1904, fala-nos sob a perspectiva de uma corrida de automóvel e de um desastre em que o veículo cai num fosso. O segundo, Manifesto Técnico da Literatura Futurista, de 1912, adota o ponto de vista de uma viagem de avião. Tanto um como outro vão priorizar a velocidade como parte integrante da sensibilidade moderna.

Benjamim Costallat foi um espírito aberto às novidades de seu tempo. Seu texto apresenta marcas dessa abertura mediante uma sintaxe bem diferente daquela que se praticava anteriormente, mesmo nos jornais. Cumpre lembrar que ele havia sido educado em Paris, de onde retornou com as ameaças da Primeira Guerra. Suas relações com a Europa se intensificaram e, no ano de 1920, ele parte para o Velho Continente, fixando-se na França e na Itália por sete meses, de onde escrevia a coluna De lá pra cá para a Gazeta de Notícias.

A escolha estilística do autor para a confecção de seus textos muito se assemelhava àquela almejada pelo futurismo: frases curtas, com poucos adjetivos, verbos de ação, parágrafos curtos e estruturas coordenadas. Observa Costallat em Cocaína literária: "Nossas frases hoje valem pelos capítulos intermináveis dos nossos avós. E eles, avós e capítulos, eram realmente intermináveis! Tudo é síntese hoje na arte moderna. Tudo consiste em descobrir o traço dominante das coisas, dos ambientes, das paixões. (COSTALLAT, 1923, p. 155). 
A crônica de Benjamim Costallat: uma nova ideia de literatura para a ampliação do público leitor por meio de jornais cariocas, nos anos de 1920

E no exercício de sua nova proposta estética, assim nos conta a experiência de rever a estrela do music-hall francês, Gaby, nas telas do cinema: "Não hesitei. Dez tostões, como resposta o clássico bilhetezinho azul que escorrega de uma caixinha misteriosa; um programa, uma campainha, barulho, silêncio, escuridão, uma orquestra desafinada e finalmente a fita na apresentação de seus bonecos de luz... Não tardou muito e Gaby de fato reapareceu-me." (COSTALLAT, 1923, p. 181).

Essa acelerada imagística visual não tinha precedentes na nossa literatura e coadunava-se perfeitamente com a ideia de analogia literária, lançada pelos futuristas no manifesto de 1912: "Para dar movimentos sucessivos de um objeto, é necessário dar a cadeia de analogia que ele evoca, cada uma delas condensada, recolhida numa palavra essencial [...]" (BERNARDINI, 1985 p. 83).

A leitura que se pratica, a partir dessa sintaxe rápida, é mais simultânea que sucessiva, como se apreendêssemos o todo num só golpe de olhos. A avalanche de impressões a que estamos sujeitos no dia a dia de uma grande cidade modernizada é transportada para o texto, inaugurando na literatura brasileira, sem a sofisticação do modernismo canônico, o princípio do simultaneísmo, assim fundamentado no manifesto técnico da pintura futurista:

As dezesseis pessoas que vocês têm em sua volta no bonde que corre são uma, dez, quatro, três; estão paradas e se movem; vão e vêm, saltam sobre a estrada, devoradas por uma zona de sol, de lá depois tornam-se a sentar-se, símbolos persistentes de vibração universal. $\mathrm{E}$, às vezes, sobre a face da pessoa com quem falamos na rua, vemos o cavalo que passa ao longe. Os nossos corpos entram nos divãs sobre os quais nos sentamos, e os divãs entram em nós, assim como o bonde que passa entra nas casas, as quais por sua vez se arremessam sobre o bonde e com ele se amalgamam. (BERNARDINI, 1980, p. 42). 
Mário de Andrade, em dois textos cruciais para a poesia moderna brasileira, o Prefácio Interessantíssimo, de 1920, e A Escrava que não é a Isaura, de 1922 (mas publicado apenas em 1925), explora essa questão da polifonia poética ou no simultaneísmo na linguagem, que, como nos mostrou o crítico sueco Pär Bergman (1962), perpassava várias tradições artísticas - desde os simbolistas franceses até os futuristas italianos e russos - e relacionava-se com o novo contexto modernizador. Segundo Mário (apud SCHWARTZ, 1995), tornava-se necessário captar na escrita uma percepção simultânea de sensação da maneira menos linear e mimética possível. Podemos ler suas diretrizes para a nossa poesia em A Escrava que não é a Isaura:

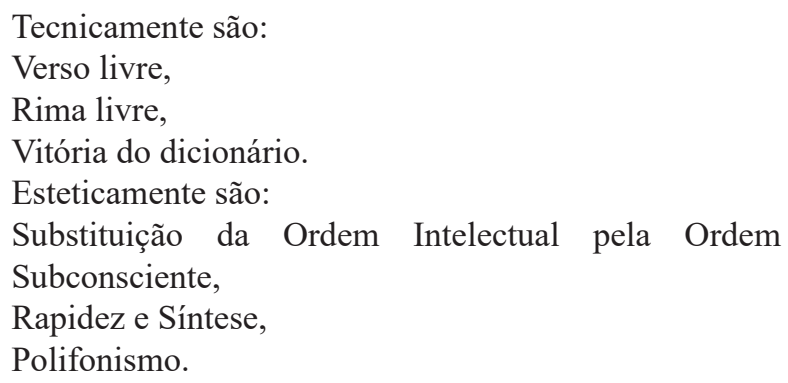
(ANDRADE apud SCHWARTZ, 1995, p. 130).

Não há dúvida de que tais procedimentos preconizados por Mário de Andrade atualizam na literatura as novas experiências estéticas cinematográficas. Contudo, importa destacar que Benjamim Costallat, autor marginal e anterior ao movimento modernista, já colocava em prática uma linguagem essencialmente cinematográfica, gerando uma ruptura na estrutura tradicional das frases. Estas se tornavam sincopadas, obedecendo à sintaxe construída analogicamente nos filmes. Seus textos estão repletos de exemplos ilustrativos dessa sintaxe por contiguidade. Lemos 
A crônica de Benjamim Costallat: uma nova ideia de literatura para a ampliação do público leitor por meio de jornais cariocas, nos anos de 1920

em À noite, numa calçada: "É noite. Largo do Rocio. Zona do teatro popular. O povo que tem cinco mil réis para se divertir está ali. Nos cafés, às portas dos espetáculos, entupindo as calçadas." (COSTALLAT, 1924, p. 65).

$\mathrm{Na}$ introdução que faz para Cock-Tail, reunião de crônicas, Costallat articula a ideia da bebida cock-tail e suas crônicas, a figura do barman e o cronista, enfatizando a importância do ritmo e da visualidade para os seus textos. Explica: "Uma mistura de cock-tail é a mistura de crônicas deste livro." (COSTALLAT, 1923, p. 11). O barman, assim como o cronista, reúne uma série de elementos e "sacode tudo com ritmo". "No cálice chato e geladinho vem se depositar, então, um líquido de todas as tonalidades, conforme a mistura; ora cor de cereja, ora cor de maçã, ora claro, ora escuro, e bebe-se tudo aquilo mais pela cor do que por outra coisa." (COSTALLAT, 1923, p. 11).

Benjamim Costallat articulava estratégias discursivas visando à ampliação de seu público. O gênero crônica, mesclando informação e ficção, conferia maior referencialidade ao enredo e seduzia o leitor para um contexto com o qual ele facilmente se identificava. Nesse sentido, o cronista também buscava esmiuçar o universo feminino da época com vistas à conquista de leitoras. A sintaxe dinâmica e imagética de Costallat - acentuada por esse gênero que tem como suporte o jornal - também marcou significativamente a expansão da recepção de seus textos já que o público, imerso no ritmo intenso da cidade, reconhecia-se na velocidade e na visualidade da narrativa. 


\section{Considerações finais}

Num sentido mais amplo, este artigo discutiu a interação entre artefatos técnicos e subjetividades no contexto do início do século XX no Brasil e avaliou em que medida essa interação marcou uma nova ideia de cultura e literatura que tem como um de seus grandes representantes Benjamim Costallat, autor marginal ao nosso movimento modernista. A produção de Costallat merece ser lida na perspectiva de uma proposta que aponta para a fragilidade de nossa modernização, que não oferecia possibilidades de educação formal para todos, inviabilizando, assim, a formação de leitores e cidadãos.

Sua produção também percebia a dificuldade da constituição de uma esfera literária entre nós, visto que esta era definida por princípios exclusivamente estéticos, de acordo com a crítica institucionalizada. Nessa esteira, o cronista avaliava que o público voltado para as letras era reduzido e insuficiente para alavancar a profissionalização do literato no Brasil, sendo necessário um novo produto cultural, nos jornais do Rio de Janeiro, que articulasse o cotidiano, os hábitos e costumes da cidade numa sintaxe marcada pelos novos ritmos e imagens urbanas. Assim, Costallat trouxe para a cena literária, num movimento inédito no país, uma nova proposta textual que se coadunava com seu projeto de ampliação da comunidade leitora, inspirada pelo movimento futurista de vanguarda, mas fortemente atenta à nossa realidade. Desse modo, a produção do nosso cronista constitui uma nova manifestação literária que não deve ser avaliada estritamente segundo os critérios estéticos adotados pela crítica modernista canônica. É necessário analisar a partir de outras perspectivas esses textos que fogem ao 
A crônica de Benjamim Costallat: uma nova ideia de literatura para a ampliação do público leitor por meio de jornais cariocas, nos anos de 1920

convencionalismo das categorias de arte tradicional, sob pena de negação da reinvenção de uma prática vanguardista no Brasil que lança luzes sobre as incongruências de um projeto autoritário de modernização entre nós.

\section{Referências}

BAUDELAIRE, Charles. Poesia e prosa. Rio de Janeiro: Nova Aguilar, 2006

BAUDELAIRE, Charles. Salão de “1859”. In: A Modernidade de Baudelaire. Apresentação de Teixeira Coelho. Tradução de Suely Cassal. Rio de Janeiro: Paz e Terra, 1988.

BENJAMIN, Walter. A modernidade e os modernos. Rio de Janeiro: Tempo Brasileiro, 1975

BERGMAN, Pär. Modernolatria e Simultaneità. Upsala: Svenska Bokförlaget, 1962.

BERNARDINI, Aurora Fornoni (org). O Futurismo Italiano. São Paulo: Perspectiva, 1985.

BEUVE, Sainte. Le siècle du progrès. Paris: Hermann, 1992.

BÜRGER, Peter. Teoría de la Vanguardia. Editorial Las Cuarenta: Buenos Aires, 2019.

COELHO, Teixeira. A modernidade de Baudelaire. Rio de Janeiro: Paz e Terra, 1988.

COSTAllat, Benjamin. Depois da meia noite... Rio de Janeiro: Guanabara, 1922.

COSTAllat, Benjamin. Cock-tail. Rio de Janeiro: Leite Ribeiro, 1923.

COSTAllat, Benjamin. Mutt, Jeff \& Cia (crônicas). Rio de Janeiro: Leite Ribeiro, 1922 
COStallat, Benjamin. Mistérios do Rio. Rio de Janeiro: Biblioteca Carioca, 1990.

COSTALLAT, Benjamin. Dora, pedacinho de gente... Rio de Janeiro: Guanabara, 1924

COUTINHO, Afrânio. A literatura no Brasil. Rio de Janeiro: Global, 2001.

JAY, Martin. ¿qué significa estetizar la política? In: JAY, Martin. Campos de Fuerza. Entre la historia intelectual y la critica cultural. Buenos Aires/ Argentina/ Mexico/ Barcelona: Paidós, 2003. 143-165.

LAURITO, Ilka; BENDER, Flora. Crônica. História. Teoria e Prática. São Paulo: Scipione, 1993.

LUSTOSA, Isabel (org.). Introdução. In: FRADIQUE, Mendes. História do Brasil pelo método confuso. São Paulo: Companhia das Letras, 2004.

MICHELI, Mario de. Le avanguardie astistiche del Novecento. Milano: Feltrinelli, 2003.

ORTIZ, Renato. A moderna tradição brasileira. São Paulo: Brasiliense, 2001.

ORTIZ, Renato. Cultura e modernidade. São Paulo: Brasiliense, 1991.

PASSOS, Marta. O canto da sereia: as crônicas de José de Alencar na formação de um público leitor e na definição de hábitos e costumes na sociedade. Dissertação (Mestrado em Letras) - Universidade do Estado do Rio de Janeiro, Rio de Janeiro, 2000.

SCHWARTZ, Jorge. Vanguarda e cosmopolitismo. São Paulo: Perspectiva, 1983.

SCHWARTZ, Jorge. Vanguardas Latino-America. São Paulo: Iluminuras/ Edusp/ FAPESP, 1995. 
A crônica de Benjamim Costallat: uma nova ideia de literatura para a ampliação do público leitor por meio de jornais cariocas, nos anos de 1920

SILVA, Mauricio. Benjamin Costallat: o primeiro autor Kitsch da literatura brasileira. Ciência e Letra. Porto Alegre, n. 20, p.101-108, 1997.

SUSSEKIND, Flora. Cinematógrafo de Letras. São Paulo: Companhia das Letras, 1987. 